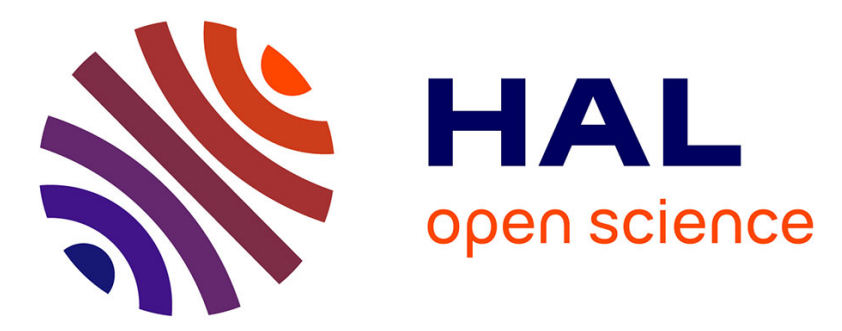

\title{
Polarization Reconfiguration of a Millimeter-Waves Antenna using the Optical Control of Phase Change Materials
}

Jehison Leon-Valdes, Laure Huitema, Eric Arnaud, Damien Passerieux, Aurelian Crunteanu

\section{To cite this version:}

Jehison Leon-Valdes, Laure Huitema, Eric Arnaud, Damien Passerieux, Aurelian Crunteanu. Polarization Reconfiguration of a Millimeter-Waves Antenna using the Optical Control of Phase Change Materials. 2020 14th European Conference on Antennas and Propagation (EuCAP), Mar 2020, Copenhagen (on line), Denmark. 10.23919/EuCAP48036.2020.9135811 . hal-03025507

\section{HAL Id: hal-03025507 https://hal.science/hal-03025507}

Submitted on 27 Nov 2020

HAL is a multi-disciplinary open access archive for the deposit and dissemination of scientific research documents, whether they are published or not. The documents may come from teaching and research institutions in France or abroad, or from public or private research centers.
L'archive ouverte pluridisciplinaire HAL, est destinée au dépôt et à la diffusion de documents scientifiques de niveau recherche, publiés ou non, émanant des établissements d'enseignement et de recherche français ou étrangers, des laboratoires publics ou privés. 


\title{
Polarization Reconfiguration of a Millimeter-Waves Antenna using the Optical Control of Phase Change Materials
}

\author{
Jehison Leon-Valdes, Laure Huitema, Eric Arnaud, Damien Passerieux, Aurelian Crunteanu \\ XLIM Research Institute, CNRS UMR 7552, University of Limoges, Limoges, France, jehison.leon@xlim.fr
}

\begin{abstract}
We present the integration of Germanium Telluride (GeTe), a phase change material (PCM), within a conventional patch antenna operating in the millimeter wave domain $(\sim 30 \mathrm{GHz})$. The GeTe is integrated within the four corners of the metallic patch, which is excited by a microstrip line. The phase changes between the insulating (OFF) and metallic (ON) states of GeTe are controlled using shorts ultraviolet (UV) laser pulses. That allows the reconfiguration of the device between a linear polarization (LP), a left hand circular polarization (LHCP) and a right hand circular polarization (RHCP). Measured results of the fabricated antenna show total efficiencies up to $75 \%$ for the circular polarization (CP) and a $3 \mathrm{~dB}$ bandwidth of axial ratio (AR) over $350 \mathrm{MHz}$ around $29.5 \mathrm{GHz}$.
\end{abstract}

Index Terms-patch antenna, polarization reconfigurability phase change material, optical activation,.

\section{INTRODUCTION}

With the increase in data traffic and communication channels diversity, more compact antenna systems with reconfigurability functions (frequency, polarization and/or radiation pattern) are needed [1]-[4]. Thus, the polarization reconfigurability (changes between left hand circular polarization (LHCP), right hand circular polarization (RHCP) and linear polarization (LP)) allows the antenna to adapt their radiation characteristics to variable environments, improves the quality and the robustness of the wireless link, allows frequency reuse, which extends the system's capabilities, and becomes useful when the operating frequency band is limited [5].

Microstrip patch antennas are suitable for communications systems due to their low volume and light weight, easy fabrication and low profile configuration which can be mounted on flat or curved surfaces. On the other hand, circular polarization (CP) can be an interesting solution for space applications to overcome misalignment between transmitter and receiver, to mitigate inherent polarization loss factors due to multipath losses [6], to overcome the effects of deflections, propagation and ground reflections for satellite applications. A circular polarization operation of an antenna can be obtained by exciting two linearly polarized orthogonal modes with equal amplitude and with a phase difference of $90^{\circ}$. Integrating disturbance zones in the main antenna structure (truncating corners or etching slots) is a common way to excite a circular polarization, as well as using magnetic materials or feeding techniques (single or multiple) [5]-[11].

In this study, we introduce an optical control of the polarization states of an antenna device integrated the GeTe phase change material (PCM) and operating in the millimeter-waves domain. PCM could open the way for more integrated systems and for frequency domains where current solutions based on PIN diodes or MEMS devices are less effective, [5], [6], [8].

\section{ELECTRICAL PROPERTIES AND OPTICAL CONTROL OF PCM}

The integration of PCM technologies into high frequencies (including millimeter-wave domain) functions is based on their capacity to change from a conductive state, ON (crystalline phase) to an insulating sate, OFF (amorphous phase). The material's properties are controlled using the application of a thermal, electrical or optical stimulus [12]-[15]. The key advantage of PCM-based devices technology is the bi-stability, i.e. they do not require a permanent bias or optical excitation to be maintained in their ON or OFF state.

Preliminary test of Germanium Telluride (GeTe) and $\mathrm{Ge}_{2} \mathrm{Sb}_{2} \mathrm{Te}_{5}$ (GST) -based RF-switches performances were already evaluated in the millimeter-wave domain [12], [14]. These materials have proven a good power handling capability, low energy consumption, high OFF state isolation, low $\mathrm{ON}$ state losses and a factor of merit greater than the current semiconductor-based switching technologies, significant variations in resistivity during insulating-to metallic phase changes (5-6 orders of magnitude), over large frequency domain (from $\mathrm{DC}$ to $\mathrm{THz}$ waves).

Thus, the GeTe material was integrated into coplanar waveguides structure (RF-PCM switches) and within a frequency agile patch antenna (PCM-based antenna device) [12]-[13]. Based on measurements results and 3D electromagnetics simulations of those devices, the GeTe layer prepared in the crystalline state have a conductivity around $4 \times 10^{5} \mathrm{~S} / \mathrm{m}$ and between 3 and $10 \mathrm{~S} / \mathrm{m}$ in the amorphous state, with a permittivity of 70 , in the $20-60 \mathrm{GHz}$ domain. 
The reversible, repetitive and reproducible transition between the metallic and insulating states in GeTe were achieved using direct irradiations of a film with short laser pulses (KrF Compex Pro110 laser, $\lambda=248 \mathrm{~nm}, 15 \mathrm{~mm} \times 5$ $\mathrm{mm}$ spot laser size, pulse duration $\sim 30 \mathrm{~ns}$ ). The crystallization of GeTe requires a single laser pulse with a surface energy density (fluence) of $90 \mathrm{~mJ} / \mathrm{cm}^{2}$. The material requires a much higher fluence for the amorphisation, around $190 \mathrm{~mJ} / \mathrm{cm}^{2}$.

The choice for an optical control of GeTe with short laser pulses is justified for specific antenna applications, in order to reduce switching times (few tens of nanoseconds) and to avoid complex manufacturing and integration of polarization lines (bias lines) related to the electrical activation of PCM, which could introduce parasitic radiation and disturb the radiation pattern of the antenna.

The previously evaluated electrical properties of GeTe have been used to design and demonstrate a polarizationtunable antenna in the millimeter wave which is described in the following chapter.

\section{Polarization Tunable Patch ANTENNA}

The proposed polarization reconfigurable antenna is designed as single-feed square metal patch $(2.5 \times 2.5 \mathrm{~mm})$ printed on a Rogers substrate (RO4003C - 12.5 x $12.5 \mathrm{~mm}$, $0.305 \mathrm{~mm}$ thick), excited by a microstrip line and operating around $29.5 \mathrm{GHz}$. The GeTe was incorporated on each truncated corner of the metallic patch, having an equal side length $(0.45 \mathrm{~mm})$ as shown in Fig.1. A cross-slot pattern (width and length conveniently optimized ) was also etched from the center of the patch and replaced by the amorphous $\mathrm{GeTe}$, in order to improve the bandwidth of the antenna $\left(\left|\mathrm{S}_{11}\right|<-10 \mathrm{~dB}\right)$ and the bandwidth of the circular polarization $(\mathrm{AR}<3 \mathrm{~dB})$. The antenna device was manufactured in the clean room of the XLIM Laboratory using microfabrication techniques.

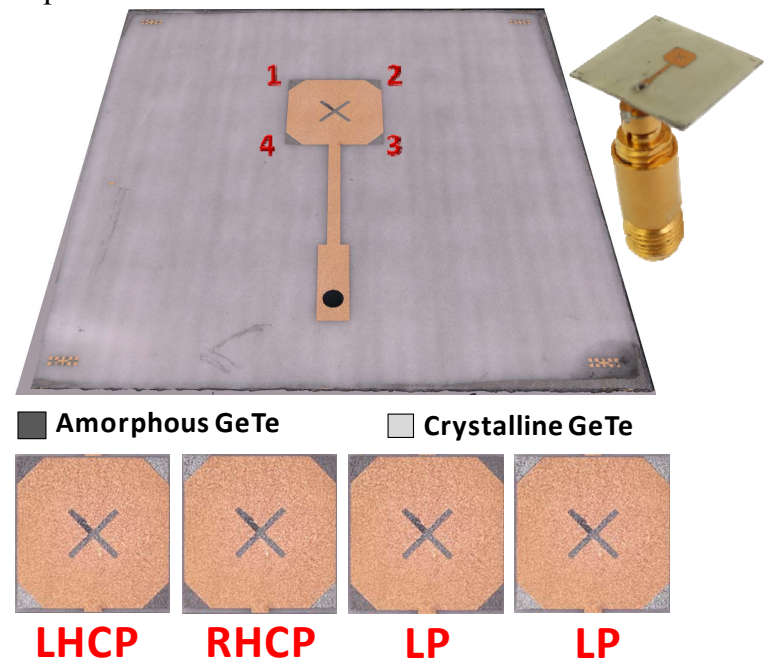

Fig. 1. Fabricated polarization reconfigurable antenna with a SMP-type connector integrated in the back. Overview of the composite patch with the amorphous GeTe patterns (dark grey color) in the four corners and the different four configurations of the device following locally crystallization of GeTe patterns using laser pulses (light grey colors).

The phase changes of GeTe patterns between their OFF and $\mathrm{ON}$ states using direct laser irradiation and a proximity contact hard mask, allow changing the overall geometry of the patch. In this way, the antenna presents a LP when the four GeTe corners are in the same state (insulating or metallic). When the four corners of GeTe are amorphous the operating frequency of the device is around $30.4 \mathrm{GHz}$, and around $29.5 \mathrm{GHz}$ when they are crystalline. When activating two opposite GeTe corners in the ON state while keeping the other two in the OFF state, the antenna will operate with a LHCP or a RHCP. Indeed, changing the symmetry of the antenna allows the installation of two orthogonal degenerated modes $\left(\mathrm{TM}_{01}\right.$ and $\left.\mathrm{TM}_{10}\right)$ at the same resonant frequency and consequently, a circular polarization operation. The different operating polarization states of the antenna depend of the optically-prepared GeTe pattern configurations, as shown in Table I. One may notice from Fig. 1 the color changes of GeTe patterns subjected to the insulator-to-metal phase change. Here, dark gray corresponds to the amorphous/insulating state while the change to light gray color corresponds to the crystalline/metallic state, confirmed by local resistance measurement.

TABLE I. Four COMBINATIONS OF GeTE StATES AND THE RESULTING POLARIZATION.

\begin{tabular}{|c|c|c|c|c|c|}
\hline State & Corner 1 & Corner 2 & Corner 3 & Corner 4 & Polarization \\
\hline 1 & OFF & ON & OFF & ON & LHCP \\
\hline 2 & ON & OFF & ON & OFF & RHCP \\
\hline 3 & OFF & OFF & OFF & OFF & LP \\
\hline 4 & ON & ON & ON & ON & LP \\
\hline
\end{tabular}

From Table I, we can notice that a LHCP (State 1) is obtained by the crystallization of corners 2 and 4 and the amorphization of corners 1 and 3. Conversely, RHCP (State 2 ) is established by the crystallization of corners 1 and 3 and the amorphization of corners 2 and 4. Finally, the geometrical symmetry of the States 3 and 4 (all GeTe patterns amorphous and, respectively crystalline) is inducing a LP in the Y-direction because all corners of the structure are in the same state (OFF or $\mathrm{ON})$.

A SMP-type connector integrated at the back of the antenna (Fig. 1) allows exciting the microstrip line and measuring the antenna performances. The measured $\left|\mathrm{S}_{11}\right|$ parameter for the four configurations (Table I) are presented in Fig.2. Considering the same geometrical symmetry for States 1 and 2, the LHCP and the RHCP have similar performance with respect to operating frequency, return loss, gain, total efficiency and AR, as expected and ideally required for polarization reconfigurability applications. Due to this similarity, we will focus on State 1 (LHCP) for measurements of radiation properties. As also observed in Fig. 2, the impedance matching bandwidth of the configuration in the State 3 is shifted at higher frequency with respect to the CP (States 1 and 2) and the LP of State 4. Indeed, the global dimension of the patch in State 3 is 
smaller. Since our objective is to obtain a polarization reconfigurability for a same frequency band (here around $29.5 \mathrm{GHz}$ ), only the performance for the state 4 in LP operation will be analyzed.

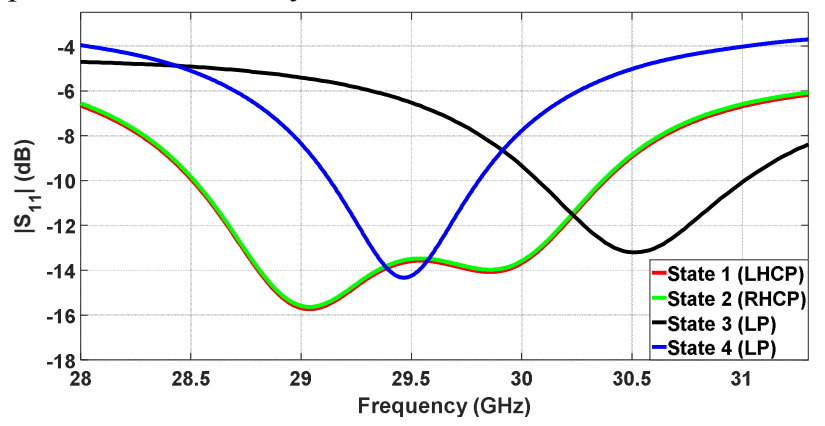

Fig. 2. Measurements results of $|\mathrm{S} 11|$ parameters for different states of GeTe patterns indicated in Table I.

A Compact Antenna Test Range (CATR) measurement system going from 8 to $110 \mathrm{GHz}$ has been used to measure radiation performances of the proposed antenna in a reception configuration. Results shown in Fig 3 are the measured 3D radiation patterns at $29.5 \mathrm{GHz}$ for State 1 (LHCP) and State 4 (LP), exhibiting typical patch antenna characteristics (a single main lobe radiated out in the $\mathrm{Z}-$ direction with a wide beam width.
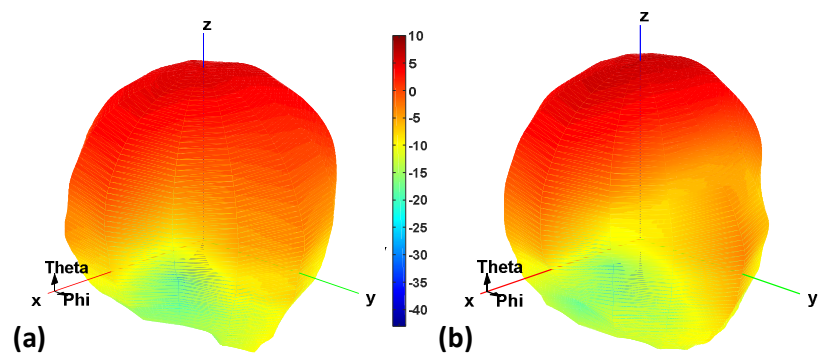

Fig. 3. 3D Gain radiation patterns measured from the proposed antenna at 29.5 GHz. (a) State 1 (LHCP). (b) State 4 (LP).

The plotted boresight $\left(\varphi=0^{\circ}, \theta=0^{\circ}\right)$ AR as function of the frequency for the LHCP configuration is shown in Fig. 4 and we can notice a bandwidth $(\mathrm{AR}<3 \mathrm{~dB})$ of $1.3 \%$ around $29.5 \mathrm{GHz}$. The RHCP antenna configuration (State 2) presents equivalent results due to the antenna symmetry (results not presented here).

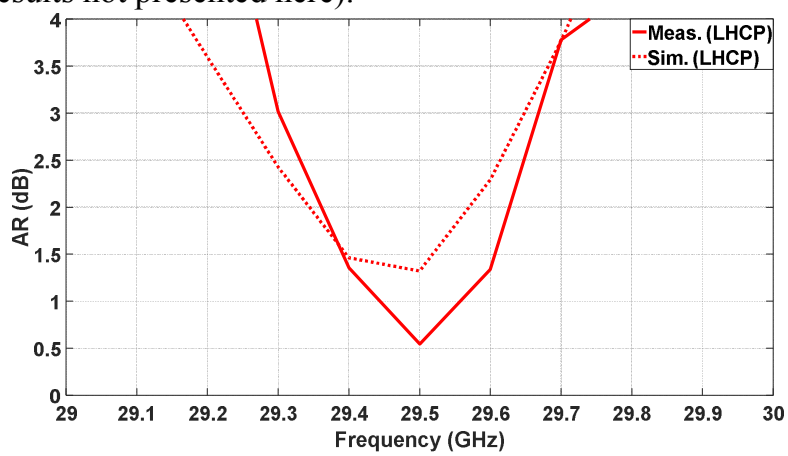

Fig. 4. Measured and simulated axial ratios (AR) of the proposed antenna for the LHCP (State 1).
To have a complete view on the antenna performance, the directivity, the realized gain and total efficiency have been measured for the different configurations. Fig. 5 plots the frequency dependence of the total efficiency for States 1 and 4 obtained in simulation and measure results. Although acceptable, the lower values of measured total efficiencies compared to the simulation results can be explained by differences in dielectric properties of GeTe obtained on the Rogers substrate compared with the GeTe material properties used for simulations (extracted from devices realized on sapphire substrate with a low-roughness).

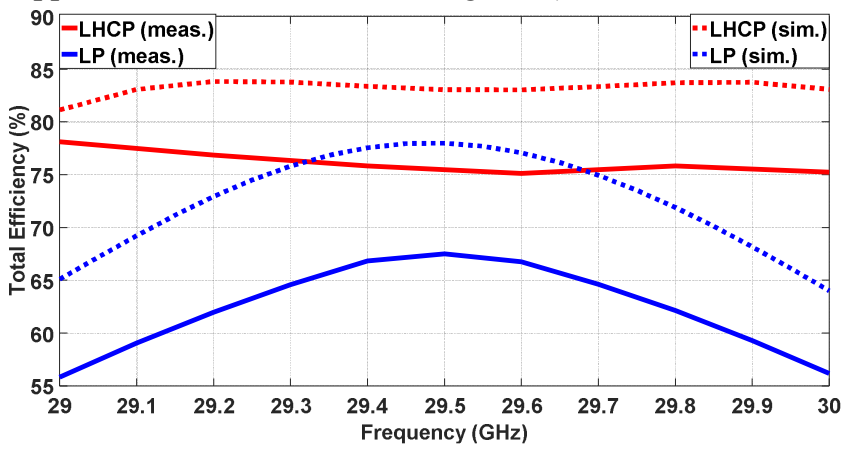

Fig. 5. Measured and simulated results of total efficiency for the circular polarization (Satate 1 - LHCP) and for the linear polarization (State $4-\mathrm{LP}$ ).

The measured performances of the antenna are summarized in Table II, regarding $-10 \mathrm{~dB}$ impedance bandwidth, $3 \mathrm{~dB}$ bandwidth of $\mathrm{AR}$ in $\mathrm{CP}$, total efficiency and the maximum realized gain at $29.5 \mathrm{GHz}$.

TABLE II. SUMMARY OF MEASURED RESUlts FOR THE FABRICATED ANTENNA

\begin{tabular}{|c|c|c|c|c|}
\hline Polarization & $\begin{array}{c}\text { BW } \\
\left(\left|\mathbf{S}_{\mathbf{1 1}}\right|<-\mathbf{1 0} \mathbf{~ d B}\right)\end{array}$ & $\begin{array}{c}\text { BW } \\
(\mathbf{A R}<\mathbf{3} \mathbf{~ d B})\end{array}$ & $\begin{array}{c}\text { Max. Gain } \\
(\mathbf{d B})\end{array}$ & $\begin{array}{c}\text { Tot. Eff. } \\
(\mathbf{\%})\end{array}$ \\
\hline LHCP & $6.4 \%$ & $1.3 \%$ & 6.2 & 75 \\
\hline RHCP & $6.4 \%$ & $1.3 \%$ & 6.2 & 75 \\
\hline LP & $2,4 \%$ & --- & 8.3 & 67 \\
\hline
\end{tabular}

\section{CONCLUSIONS}

We designed and fabricated a hybrid metal-GeTe patch antenna operating around $29.5 \mathrm{GHz}$ for a polarization reconfigurability between a LHCP, a RHCP and a LP, depending on the different states of the integrated PCM. These states changes were optically controlled by short laser pulses in a reversible and a bi-stable manner. Thus, we proposed a simple way to realize antennas operating in the millimeter-wave domain and having, an on-demand, polarization diversity. The optimization of this device will allow to increase the AR bandwidth as well as the integration of other reconfigurability functions within the same antenna (frequency or radiation pattern).

\section{REFERENCES}

[1] W. A. Awan, A. Zaidi, N. Hussain, S. Khalid, Halima and A. Baghdad "Frequency reconfigurable patch antenna for millimeter wave applications," 2019 International Conference on Computing, Mathematics and Engineering Technologies - iCoMET, 2019. 
[2] P.-Y Qin, Y. J. Guo, Y. Cai, E. Dutkiewicz and C.-H. Liang, “A reconfigurable antenna with frequency and polarization agility", Antenna and wireless propagation letters, Vol. 10, 2011.

[3] P. K. Li, Z. H. Shao, Q. Wang and Y. J. Cheng, "Frequency and pattern reconfigurable antenna for multistandard wireless applications," IEEE Antenna and wireless propagation letters, Vol. $14,2015$.

[4] Y. I. Abdulraheem, A. S. Abdullah, H. J. Mohammed, B. Mohammed and R. A. Abd-Alhameed, "Design of radiation pattern reconfigurable $60-\mathrm{GHz}$ antenna for 5G applications," Journal of Telecommunications, Vol. 27, Issue 2, October 2014

[5] Y. J. Sung, T. U. Jang and Y.-S. Kim, “A reconfigurable microstrip antenna for switchable polarization," IEEE Microwave and wireless components letters, Vol. 14, No. 11, pp. 534-536, November 2004.

[6] W.-S. Yoon, J.W. Baik, H.-S. Lee, S. Pyo, S.-M. Hanand and Y. S. Kimm, "A reconfigurable circularly polarized microstrip antenna with a slotted ground plane," IEEE Antenna and wireless propagation letters, Vol. 9, pp. 1161- 1164, 2010.

[7] H. Wong, K. K. So, K. B. Ng, K. M. Luk, C. H. Chan and Q. Xue, "Virtually shorted patch antenna for circular polarization," IEEE Antennas and wireless propagation letters, Vol. 9, pp. 1213-1216, 2010 .

[8] K. Ming-jiang Ho and G. M. Rebeiz, “A 0.9-1.5 GHz microstrip antenna with full polarization diversity and frequency agility," IEEE Transaction on antenna and propagation, vol. 62, No. 5, pp. 23982406, May 2014.

[9] E. Aloni and R. Kastner, "Analysis of a dual circularly polarized microstrip antenna fed by crossed slots," IEEE Transactions on antennas and propagation, vol.42, No. 8, pp. 1053-1058, August 1994.

[10] E. Herth, N. Rolland and T. Lasri, "Circularly polarized millimeterwave antenna using 0-level packaging," IEEE Antennas and wireless propagation letters, vol. 9, pp. 934- 937, 2010.

[11] E. Arnaud, L. Huitema, R. Chantalat, A. Bellion and T. Monédière, "Miniaturization of a circular polarized antenna using ferrite materials", 12th European Conference on Antennas and Propagation (EUCAP), Apr 2018, London, United Kingdom.

[12] A. Crunteanu, L. Huitema, H. Wong, J.-C. Orlianges, C. Guines and D. Passerieux, "Optical switching of GeTe phase change materials for high-frequency applications," IEEE MTT-S International microwave workshopseries on advanced materials and processes, Pavia, Italy, 2022 september, 2017.

[13] L. Huitema, J. Leon Valdes, H. Wong and A. Crunteanu, "Optical switching of GeTe phase change material: Application to a frequency agile millimeter-waves patch antenna", 12th European Conference on Antennas and Propagation (EUCAP), April 2018, London, UK, At London, UK.

[14] A. Mennai, A., Bessaudou, F. Cosset, C. Guines, P. Blondy and A. Crunteanu, "Bistable RF Switches Using Ge2Sb2Te5 Phase Change Material", 18th European Microwave Week EuMW 2015, Paris, France, pp. 1-4, 2015.

[15] N. El-Hinnawy, P. Borodulin, A. Ezis, C. Furrow, C. Padilla, M. King, E. Jones, B. Wagner, J. Paramesh, J. Bain, D. Nichols and R. M. Young, "Substrate agnostic monolithic integration of the inline phase change switch technology", 2016 IEEE MTT-S Int. Microw. Symp. Dig., San Francisco, CA, USA, pp. 1-4, 2016 